\title{
CPRE sin utilización de fluoroscopia en una paciente gestante con coledocolitiasis
}

\author{
J. García-Cano, J. C. Palomo Sánchez y C. J. Gómez Ruiz \\ Sección de Aparato Digestivo y Servicio de Cirugía. Hospital Virgen de la Luz. Cuenca
}

Paciente de 31 años con una gestación de 23 semanas que ingresó por dolor en hipocondrio derecho y una alteración bioquímica colestásica. Se realizó una colangiopancreatografía por resonancia magnética (CPRM) en la que se apreciaron colelitiasis y una coledocolitiasis (Fig. 1). La realización de una colangiopancreatografía retrógrada endoscópica (CPRE) se consideró el tratamiento de elección. Se explicó a la paciente que intentaría utilizarse la mínima radiación posible. Aunque, al estar en el segundo trimestre del embarazo, la teratogenicidad de una radiación corta podía ser poca. Como en este nivel de gestación el abdomen es ya globuloso, la CPRE se realizó con la paciente en decúbito lateral izquierdo, cubriendo el abdomen con un mandil de plomo. Para canular la vía biliar se utilizó un esfinterótomo de punta fina (Autotome ${ }^{\circledR}$, sistema Rapid Exchange) cargado con una guía de 0,025 pulgadas. Con el esfinterótomo dentro de la papila, en la teórica zona del colédoco, se hizo avanzar la guía que pasó sin dificultad. Se introdujo a continuación el esfinterótomo tras la guía y se aspiró bilis, confirmando su localización biliar. Asegurando la guía para no perder la canulación biliar se retrajo el esfinterótomo y se seccionó la papila de Vater (Fig. 2). El esfinterótomo se retiró después, dejando siempre la guía dentro del colédoco (Fig. 3). Sobre la guía se pasó un balón y se extrajo la coledocolitiasis (Fig. 4). No se utilizó en ningún momento fluoroscopia.

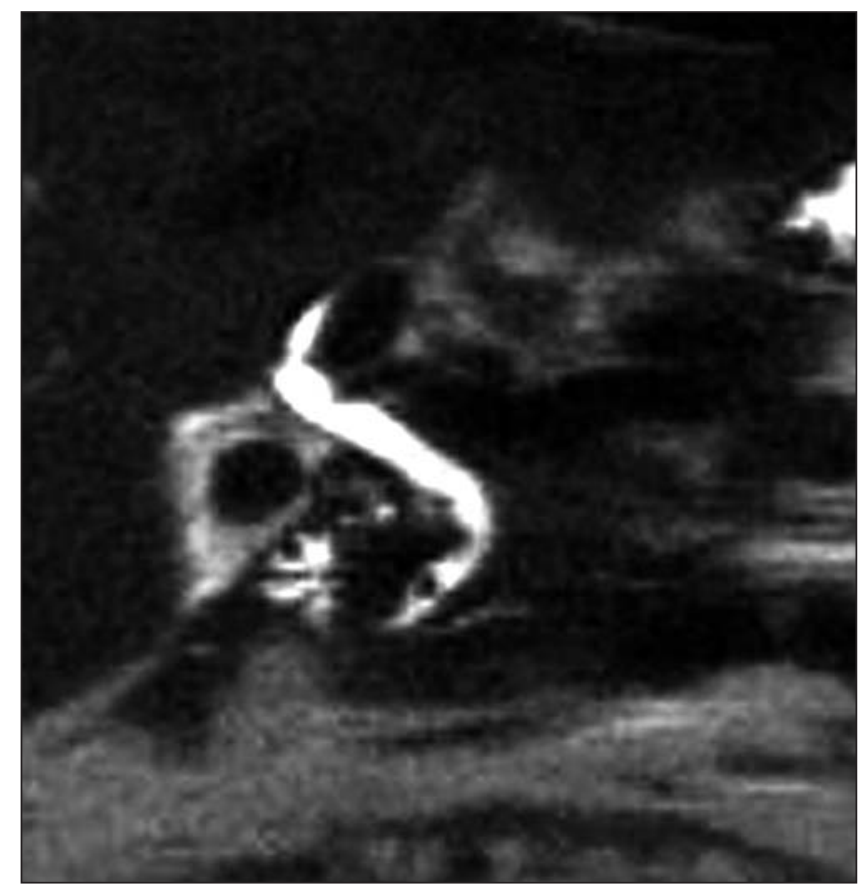

Fig. 1. Resonancia magnética abdominal en la que se observa coledocolitiasis única, litiasis en la vesícula biliar y el útero grávido.

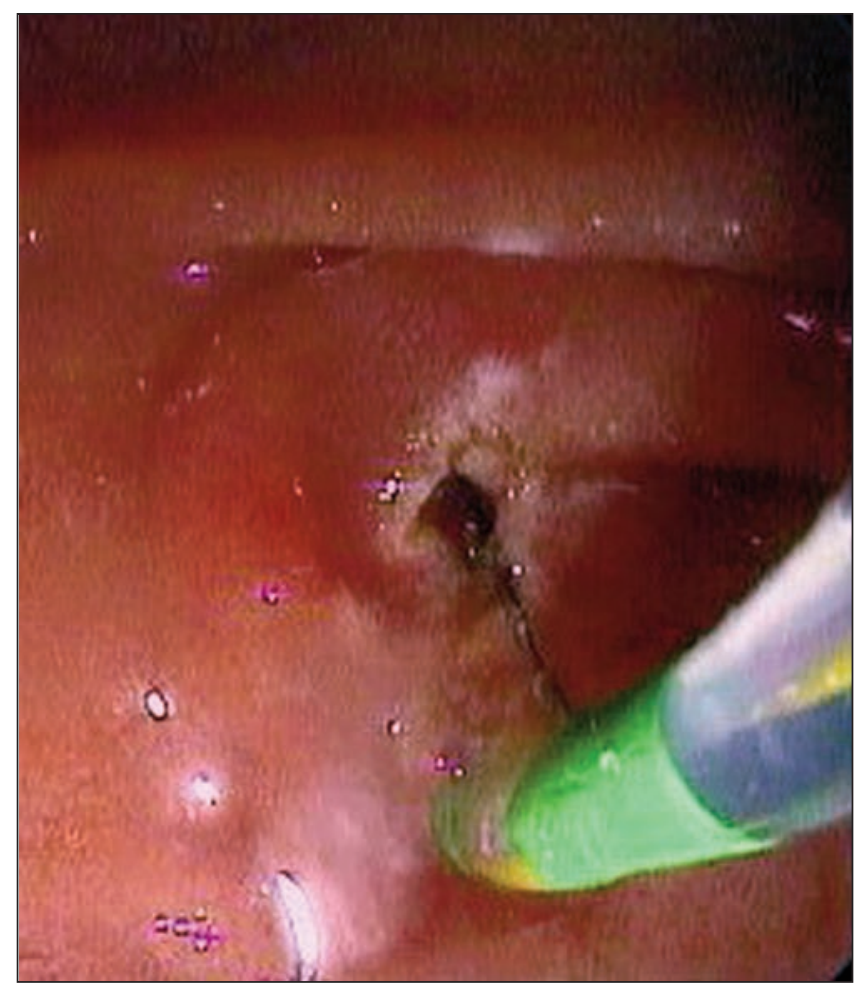

Fig. 2. Comienzo de la esfinterotomía biliar. Se observa dentro del esfinterótomo la guía que se ha insertado previamente en la vía biliar y que mantiene el acceso continuo sin necesidad de fluoroscopia. 


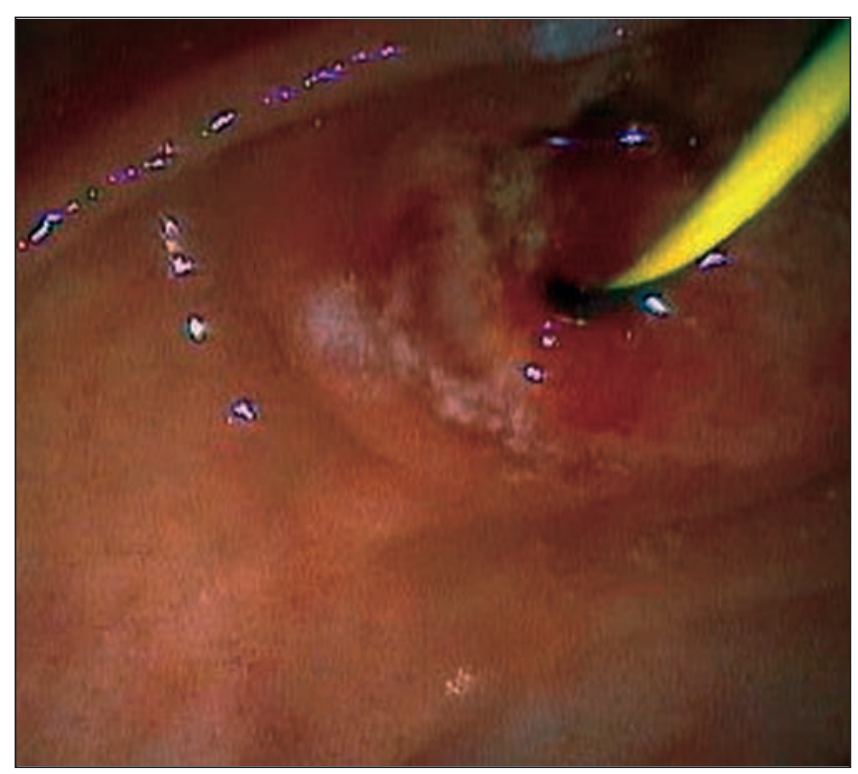

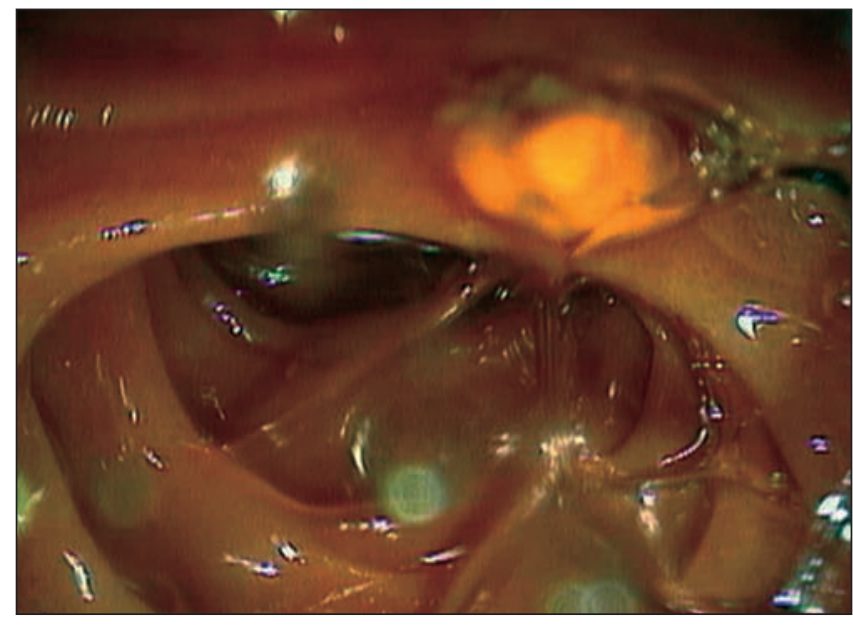

Fig. 4. Coledocolitiasis extraída en el duodeno.

Fig. 3. Tras realizar la esfinterotomía biliar se ha retirado el esfinterótomo, se mantiene la guía sobre la que se deslizará un balón para extraer la coledocolitiasis.

Con la tecnología actual para el diagnóstico de las enfermedades biliopancreáticas como la CPRM y la mejora de los instrumentos para la CPRE (1), existen algunas raras ocasiones, como la de pacientes gestantes, en que la utilización de fluoroscopia puede reducirse mucho o incluso ser completamente obviada (2).

\section{BIBLIOGRAFÍA}

1. García-Cano J, González-Martín JA. Bile duct cannulation: Success rates for various ERCP techniques and devices at a single institution. Acta Gastroenterol Belg 2006; 69: 261-7.

2. Simmons DC, Tarnasky PR, Rivera-Alsina ME. Endoscopic retrograde cholangiopancreatography (ERCP) in pregnancy without the use of radiation. Am J Obstet Gynecol 2004; 190: 1467-9. 